\title{
COMPLEXIDADE LOGÍSTICA NAS OPERAÇÕES DE MANUTENÇÃO DE PAZ: UM DESAFIO
}

\author{
Mauro Cesar Barbosa Cid ${ }^{1}$ \\ Luiz Rogério Goldoni²
}

\section{Introdução}

O século XXI continuou a ver um incremento nas missões de paz conduzidas pelas Organizações das Nações Unidas, tanto em quantidade como em complexidade, fenômeno iniciado após a queda do Muro de Berlim (Leslie 20I2). Tais aumentos afetam diretamente o planejamento e a condução das operações de paz.

Dentro desse contexto, a logística deve se adaptar à natureza dinâmica e à complexidade política de cada cenário operacional que se apresenta para as operações de paz. A determinação do suporte logístico para cada missão depende da origem e da responsabilidade do apoio à força empregada; isto, por sua vez, causa impactos diretos sobre as ações operacionais demandadas (Patriota 2009).

O apoio logístico é crucial para permitir que civis, militares e a força policial que participam das Operações de Manutenção de Paz (OMP) possam cumprir de maneira completa o mandato previsto pela ONU. Esse apoio é igualmente fundamental para preservar a capacidade operacional e a seguran-

\footnotetext{
I Doutorando do Programa de Pós-Graduação na Escola de Comando e Estado-Maior (ECEME). Especialista em Guerra Irregular (Curso de Forças Especiais, 2003) e em Ações de Comandos (2002) pelo Centro de Instrução de Operações Especiais do Exército Brasileiro. Atuou como Observador Militar e Oficial de Ligação da Operação das Nações Unidas no Chipre (UNFICYP) entre os anos de 2012 e 2013 e contribuiu no planejamento de envio de militares brasileiros para a Força Interina das Nações Unidas no Líbano (UNIFIL) em 20I4. E-mail: maurocid@ gmail.com

2 Professor do Programa de Pós-Graduação em Ciências Militares (PPGCM) do Instituto Meira Mattos, da Escola de Comando e Estado-Maior do Exército (IMM/ECEME-Brasil). É um dos editores da Coleção Meira Mattos (http://www.eceme.ensino.eb.br/meiramattos/index.php/ RMM/index). E-mail: luizrfgoldoni@gmail.com
} 
ça do pessoal civil empregado no "teatro de operações" (Neves 2009).

O objetivo deste trabalho é analisar a complexidade do apoio logístico nas OMP sob a égide da ONU. Inicialmente, para atingir a meta proposta, será apresentado um arcabouço teórico básico dos conceitos de logística no ambiente das operações de paz das Nações Unidas. Seguindo essa linha de pensamento, buscar-se-á levantar os desafios que afetam a logística em apoio às OMP. Após essas etapas, será possível analisar como a complexidade da logística afeta o curso dessas operações.

O artigo não buscará soluções para os desafios levantados, mas abordará de forma sumária algumas opções apresentadas pela ONU para resolver esses desafios.

\section{Conceitos e definições}

O conceito de "peacekeeping" (ou manutenção da paz) foi retratado de forma ampla no documento "Agenda para a paz"3. Segundo o texto de I992, assinado pelo ex-Secretário Geral das Nações Unidas, Boutros Boutros-Ghali, "peacekeeping" seria o:

[...] emprego de militares, policiais e civis para auxiliar na implementação de acordos de cessação de hostilidades. É realizado com o consentimento das partes envolvidas no conflito e pauta pela imparcialidade de suas ações. As forças internacionais utilizam-se da força apenas para sua autodefesa (Boutros-Ghali I992, tradução nossa).

O emprego de militares, policiais e civis em OMP está condicionado a um acordo de paz ou de imposição de cessar-fogo. O emprego de tropas de paz faz-se pela necessidade de garantir o respeito ao cessar-fogo e propiciar o ambiente necessário à negociação de acordo de paz e para que os peacekeepers possam entrar em cena para assegurar a implementação das medidas acordadas pelas partes beligerantes (Neves 2009).

Ainda sobre a "Agenda para a Paz", Boutros-Ghali descreveu o aumento do tamanho, do escopo e da complexidade das missões de paz da ONU e definiu três tipos de missões com ligação para a "manutenção da paz": a diplomacia preventiva, a manutenção da paz e a pacificação. Em I995, em outro documento, "Suplemento da Agenda para a Paz", termos adicionais, tais como a construção da paz, imposição da paz e o reforço da paz e do desar-

3 Documento apresentado em I992 com sugestões de como a ONU poderia reagir a conflitos violentos. 
mamento foram introduzidos, ampliando ainda mais o alcance das missões agora realizadas no todo, ou em parte, pela ONU.

A manutenção da paz situa-se entre uma série de atividades realizadas pelas Nações Unidas e outros atores internacionais para manter a paz e a segurança internacional em todo o mundo. O Manual de Princípios e Diretrizes das Operações de Manutenção de Paz das Nações Unidas (United Nations 20IOa) $)^{4}$, conhecido também como "Capstone Doctrine", cita a importância de compreender como os vários conceitos se relacionam e se diferenciam entre si. Nele há definições sobre prevenção de conflitos (conflict prevention) processo de pacificação (peacemaking) ${ }^{6}$, imposição da paz (peace enforcement) ${ }^{7}$, construção da paz (peacebuilding) ${ }^{8}$ e manutenção da paz (peacekeeping). Segundo o "Capstone Doctrine”, a manutenção da paz:

[...] é uma técnica destinada a preservar a paz, por mais frágil que seja, onde os combates tenham sido interrompidos, e [tem por objetivo] ajudar na implementação dos acordos alcançados pelas partes beligerantes. Ao longo dos anos, a manutenção da paz evoluiu de um modelo principalmente militar de observação do cessar fogo e de separação de forças após as guerras interestatais, para incorporar um modelo complexo composto por muitos elementos - militares, policiais e civis - que trabalham em conjunto para criar os alicerces de uma paz sustentável (United Nations 20Ioa, I8, tradução nossa).

Segundo Coleman $(2014,2)$, dentro de um contexto de operação de paz, a logística é "a ciência do planejamento e da execução da movimentação e manutenção do pessoal e equipamentos em operações”.

A logística, de maneira geral, sofre influências de vários aspectos que

4 O Manual em questão foi lançado e aprovado em janeiro de 2008 . Utiliza-se no presente artigo a edição revisada em janeiro de 20 ı.

5 "A prevenção de conflitos envolve a aplicação de medidas estruturais ou diplomáticas para evitar que tensões e disputas intraestatais ou interestatais evoluam para um conflito violento" (United Nations 20I0a, I7, tradução nossa).

$6 \mathrm{O}$ processo de pacificação inclui medidas para resolver conflitos em andamento e envolve ações diplomáticas para realizar um acordo negociado entre as partes hostis (United Nations 2010а).

7 A imposição da paz envolve a aplicação, com a autorização do Conselho de Segurança das Nações Unidas, de uma série de medidas coercitivas - incluindo o emprego de força militar objetivando a restauração da paz e da segurança internacionais (United Nations 20Ioa).

8 A construção da paz é um processo complexo e de longo prazo. Um dos componentes desse processo é a análise das causas estruturais dos conflitos violentos. As medidas de consolidação da paz procuram reforçar a capacidade do Estado para exercer eficaz e legitimamente suas funções essenciais (United Nations 20I0a). 
caracterizam o ambiente em que o apoio será prestado. A complexidade política e a natureza dinâmica de cada cenário operacional; a geografia topográfica e as variações climáticas de teatros de operações; a quantidade de países envolvidos e a grande variação das normas e procedimentos operacionais e de logística; a língua e as diferenças de comunicação são aspectos que tem repercussão direta em como a logística será planejada e executada, sendo importante sua análise e estudo (Leslie 20I2).

Ainda conforme Leslie (2OI2), as missões da ONU podem variar em tamanho de um pequeno grupo de observadores a uma grande operação conjunta e/ou combinada ${ }^{9}$ com tropas terrestres, aéreas e navais, envolvendo milhares de pessoas entre civis e militares. Qualquer conceito de logística terá de ser adaptado para uma missão específica tendo em conta a tarefa operacional, espaço e tempo, mão de obra, material, meio-ambiente, clima, infraestrutura e os recursos disponíveis.

Tendo em vista o suporte às missões de grande envergadura, em novembro de 1994, a Assembleia Geral da ONU aprovou a criação de uma Base Logística Permanente em Brindisi, Itália (United Nations I994). A Base Logística das Nações Unidas (UNLB) foi inicialmente um local para concentração de suprimentos. O papel da UNLB foi expandido em 2002 para incluir a criação de um conceito Estratégico de Desdobramento de Estoque (Strategic Deployment Stocks - SDS). O SDS é a reserva de material das Operações de Manutenção da Paz das Nações Unidas, que apoia uma implantação rápida e a capacidade operacional inicial de uma missão de paz complexa. Os armazéns da UNLB fornecem apoio aéreo para as missões de paz, além de realizarem treinamento logístico no âmbito da ONU (Leslie 20I2; Baig 20IO).

O suporte logístico é focado no in-service e na logística operacional, que, conforme Coleman (20I4), compreendem:

- Aquisição, armazenagem, distribuição, manutenção e evacuação dos equipamentos e materiais necessários para o funcionamento das operações;

- Transporte de pessoal para dentro e para fora da missão da operação;

- Aquisição ou construção, manutenção, operação e alienação de instalações incluindo moradias e armazéns;

- Aquisição ou fornecimento de serviços, tais como alimentação, limpeza, e serviços postais e

- Apoio médico.

9 Operações conjuntas envolvem o emprego coordenado de elementos de mais de uma força singular (terrestre, naval e aéreo) com propósitos interdependentes ou complementares. Já operações combinadas são aquelas compostas por elementos de forças armadas de mais de um país. 


\section{Apoio Logístico nas Operações de Paz}

O primeiro passo para o planejamento logístico dentro de uma operação da ONU começa no Department of Peacekeeping Operations (Departamento de Operações de Manutenção de Paz, DPKO), através do Office of Mission Support (Escritório de Suporte à Missão, OMS), onde são levantadas as necessidades do Apoio Logístico para as tropas empregadas. O órgão detalha orientações e mecanismos de monitoração para as estruturas na região de operações e busca promover uma gestão eficiente e eficaz dos recursos durante toda a missão (United Nations 2003).

Em seguida é estabelecido um Memorandum of Understanding (Memorando de Entendimento, MOU), que consiste em um acordo entre o país contribuinte e a ONU. O MOU define o tipo e o nível de apoio a ser prestado, bem como as responsabilidades associadas a cada um dos entes. O Manual da ONU de Operações de Paz em ambiente Mutidimensional (United Nations 2003) explica que o Memorandum contém detalhes sobre pessoal, equipamentos e serviços, bem como os valores que cada nação contribuinte irá receber pela participação na missão. Além desse documento, pode também ser assinada uma Letters of Assist (Carta de Assistência, LOA) entre a ONU e o governo do país contribuinte para o fornecimento de bens específicos ou de serviços que não constem no MOU. Surge ainda como alternativa ao apoio logístico os Memorandum of Agreements (Memorandos de Acordos, MOA) que são estabelecidos entre duas ou mais nações acordando os apoios prestados de uma nação para outra (United Nations 2003).

Todas as missões da ONU apresentam na sua composição um Chief Administrative Officer (Escritório do Chefe Administrativo, CAO), que é o responsável por todo o apoio Administrativo-Logístico. Ao CAO cabem, entre outras, as seguintes tarefas: gerir e controlar os recursos humanos, materiais e financeiros da missão; aconselhar o comandante da missão nas áreas financeira e orçamental e implementar um sistema interno de controle e transparência na utilização dos recursos da missão (United Nations 2003).

Nas operações de paz contemporâneas, o apoio logístico pode ser propiciado por estados ou pela própria ONU. No que tange as fontes de apoio logístico, o manual "Logistical Support to United Nations Peacekeeping Operations” (Suporte Logístico para as Operações de Manutenção da Paz das Nações Unidas) (Baig 20ıo) cita os seguintes tipos de fornecimento de apoio logístico:

a) Apoio logístico prestado pelos países participantes: Um Estado pode forne- 
cer amplo apoio logístico para suas tropas em toda região de operação ou em uma área específica. Os países também podem fornecer capacidades específicas, como as físicas (unidades médicas ou de engenharias) ou de gestão (por exemplo, controle de movimento).

\section{b) Apoio logístico prestado pela organização internacional coordenadora da operação: Esse tipo de apoio é baseado no fornecimento de materiais como tendas, geradores, veículos e equipamentos médicos. Além do material, a ONU pode ajudar no gerenciamento da logística através de planejamento, compras, controle de movimento e gestão da cadeia de fornecimento (supply chain management).}

c) Apoio logístico prestado pela nação anfitriã: A nação anfitriã tem uma grande importância na estruturação da logística em seu território. Esse apoio está intimamente ligado a permissão e utilização das estruturas logísticas do país, tanto para fins de transporte como para instalações e acomodações. A utilização do espaço aéreo, aeroportos, estradas e vias férreas é de vital importância para o desdobramento logístico e operacional da tropa no país. Da mesma forma, o país anfitrião poderá fornecer suprimentos de água e combustível e serviços, como médico e de engenharia. Empresas locais podem ser contratadas pela ONU para prover apoio necessário para as demandas das tropas no país ${ }^{\mathrm{IO}}$.

d) Doadores: Alguns Estados podem contribuir com equipamentos pesados, transporte estratégico ou tático e outros tipos de apoio logístico. Um exemplo é a Agência Federal de Socorro Técnico da Alemanha (Germany’s Federal Agency for Technical Relief) que auxiliou na construção das instalações que serviram de moradia para o pessoal civil da missão de paz no Sudão (Marginean 20I0).

Io Kress (2002) escreve sobre as "três opções da logística de defesa": obter os recursos necessários no campo de batalha; carregar os recursos com a tropa; enviar os recursos de uma área distante para ser distribuído entre as tropas no campo de batalha. O autor ressalta que a logística moderna deve se basear em uma combinação das três opções. A versão contemporânea do primeiro método "obter no campo de batalha" diferencia-se da praticada nas batalhas da antiguidade, nas quais os principais recursos utilizados eram água, alimentos, forragem para os animais, pedras e pedaços de madeira encontrados no "teatro de operações". "Pilhagem e extensa procura por alimentos e provisões, como principal fonte de sustentação, foram transformadas em confiança parcial sobre os recursos da nação anfitriã” (Kress 2002, I4, tradução nossa), em situações de projeção de forças e em missões de paz. 
e) Empresas contratadas: Em 20I3, as despesas da ONU com contratos e compras superou os US\$2,4 bilhões. As empresas contratadas podem ser da nação hospedeira ou do país contribuinte. Um exemplo foi a contratação da DynCorps Internacional para fornecer o transporte estratégico para a missão na Somália (Clemente 20I4).

\section{Desafios críticos para o Apoio Logístico}

Da mesma maneira que as Operações de Paz são altamente complexas, tanto pelas características multinacionais como pela volatilidade e hostilidade do ambiente operacional, o apoio logístico segue pela mesma linha de complexidade no seu planejamento e execução. De acordo com Coleman (20I4), são levantados três grandes desafios para o apoio logístico eficaz nas missões de operações de paz: I) Dificuldade de um rápido desdobramento logístico; 2) Apoio Logístico, Procurement (Aquisição) e Impactos para o país hospedeiro; e, 3) O uso de tecnologias para reduzir os desafios logísticos. A seguir, esses desafios são analisados.

\section{Dificuldade de um rápido desdobramento logístico}

Um dos grandes desafios é a dificuldade para um rápido desdobramento na área de operações. A fase inicial de uma operação de paz é crítica para o estabelecimento da logística ${ }^{\text {II }}$. Uma grande quantidade de pessoal e material deve ser transportado para o país anfitrião, onde sua chegada e todo seu movimento para a área de operações deve ser apoiado. A instalação de um suporte logístico básico com o arredamento de edifícios, infraestrutura para acampamentos, estradas, aeródromos e armazéns, torna-se especialmente difícil em áreas remotas (Coleman 20I4).

A velocidade de instalação e desdobramento passa a ser um desafio central. Nas palavras de um funcionário da ONU "eventualmente nós sempre conseguiremos o que precisamos - o problema é obtê-lo rápido" (Boutellis 20I4).

A velocidade para desencadear uma operação da ONU está intimamente ligada à avaliação com precisão de quais são as capacidades de apoio disponível do país anfitrião. Uma das soluções para esse problema é aumen-

\footnotetext{
II Conforme especialistas (Banomyong e Sodapang 20I2; Beresford e Pettit 20I2; Zeimpekins, Ichoua e Minis 20I3; Sebbah et al. 20I3), as primeiras 72 horas são críticas em uma operação de ajuda humanitária pós desastres naturais.
} 
tar a cooperação "intermissão". Com isso, especialistas já empregados em outras missões seriam temporariamente transferidos para realizar as avaliações logísticas das necessidades iniciais. Para que seja realizado esse tipo de cruzamento, a nova missão deve arcar com todos os custos, o que tem gerado problemas administrativos com o Comitê Consultivo sobre as Questões Administrativas e Orçamento (ACABQ) que se opõe a redistribuição temporária de especialistas (United Nations 20I4e). Da mesma forma, as missões existentes relutam em liberar seus especialistas, mesmo que temporariamente, o que, além dos custos, podem gerar problemas nas capacidades operacionais da missão que cede o especialista (United Nations 2014a.).

Ademais da demora para receber os equipamentos, existe o problema da capacitação de pessoal para emprego desse material. Desta forma, a cooperação intermissão oferece uma solução parcial: pessoal e equipamentos com as devidas capacidades já desdobrados em uma outra missão poderiam ser transferidos para uma nova operação para proporcionar as capacidades necessárias (United Nations 20I4e). No entanto, de acordo com Coleman (20I4), experiências práticas têm mostrado que existem limitações no potencial real da cooperação intermissão. As missões remetentes perdem poder de combate, o que muitas vezes não pode ser admitido tendo em vista que as missões funcionam com o justo e necessário, baseado na pressão persistente sobre as operações da ONU para "fazer mais com menos" e a dificuldade econômica de alguns contribuintes financeiros importantes.

A solução de utilizar a cooperação exige o consentimento do Estado membro contribuinte, que dependendo de seu processo de aprovação interna pode levar um tempo considerável que impossibilitaria o desdobramento logístico em prazo oportuno.

Outra medida para tentar aumentar a capacidade logística da ONU está ligada a criação de uma lista de peritos de logística potencialmente disponíveis para missão "start-up”, que teriam a incumbência de realizar uma avaliação técnica e implantar uma missão de paz em qualquer lugar do mundo. Essa lista incluiria especialistas da ONU com expertise em logística que estão aposentados ou em outras funções. Esses profissionais teriam, desta forma, a experiência e a capacidade de analisar o ambiente e poderiam apresentar soluções logísticas para um determinado tipo de missão (Coleman 20I4) I2 $^{\mathrm{I}}$.

Seguindo o exemplo da OTAN, a ONU passou a reunir informações sobre as possibilidades de apoio logístico no país anfitrião. A OTAN facili-

I2 Muitos militares da reserva atuam como agentes logísticos em missões de paz. Além de suas experiências, esses profissionais contribuem para aproximar e dirimir controvérsias entre as interações das organizações humanitárias com as corporações militares (Balcik et al. 20ıо; Barber 2012; Heaslip e Barber 2013). 
ta a logística de planejamento com antecedência de uma crise, incentivando membros e parceiros a desenvolver um "Capability Cataloque" (Catálogo de Capacidades) (OTAN 20IO). A sugestão, descrita por Coleman (20I4), é que esse processo seja iniciado em regiões que experimentam grande instabilidade, facilitando ao componente logístico seu rápido desdobramento.

Outra medida para agilizar e facilitar o rápido emprego dos meios logísticos é a contratação de empresas do setor privado de serviços em âmbito global com grande mobilidade e expertise logística. Como uma contratação é demorada, os contratos prévios especificam a entrega de determinados bens ou serviços para potenciais missões e pode ser ativado quando necessário para implementar uma missão ou reforçar a capacidade da ONU. No entanto, os contratos de sistemas globais são caros e os contratantes podem recusar-se a implantar (ou aumentar taxas) em condições especialmente perigosas ${ }^{13}$. Do ponto de vista prático, a contratação do setor privado tornou-se uma ferramenta vital para os governos nacionais e organizações internacionais nas missões de manutenção da paz. O setor privado está envolvido em um amplo espectro de atividades logísticas, que pode ir desde o tratamento médico até o aluguel de aeronaves (Brooks e Mangan 20II), dando grande flexibilidade e rapidez para a implementação de uma missão de paz.

Boutellis (20I4) afirma que não existe substituto viável para uma prontidão dos Estados em fornecer os elementos logísticos críticos e capazes de manter grandes contingentes durante as fases iniciais de uma missão de paz. A ONU fornece apoio logístico para as operações, incluindo gêneros de primeira necessidade como rações, combustíveis e água, além de veículos e outros equipamentos através de seus Strategic Deployment Stores (Armazém Estratégico de Desdobramento), localizados em suas Bases Logísticas ${ }^{\mathrm{I}}$. Da mesma forma, a ONU assume a responsabilidade financeira para o transporte de pessoal e material para a área de operações e reembolsa os Estados em seus custos de implantação de Contingent Owned Equipament (Materiais de Propriedade do Contingente). No entanto, isso não substitui a vontade do Estado em manter suas tropas autossustentáveis por período inicial de 90 dias, até que os sistemas de abastecimento possam se estabelecer (Boutellis 20I4).

\footnotetext{
I3 Para evitar a total dependência de terceiros, a Agência Federal da Alemanha de Técnicos de Socorro, por exemplo, mantém uma equipe especializada na construção de acampamentos de operações de paz. Para maiores informações, ver: Bundesanstalt Technisches Hilfswerk, "Standing Engineering Capacity". Disponível em: www.thw.de/SharedDocs/ Einheiten/DE/ Ausland/SEC.html?nn=206I858.

I4 As Bases Logísticas da ONU estão compreendidas dentro do Centro de Assistência Global das Nações Unidas (UNGSC). As Bases localizam-se em Brindisi (UNLB) e Valência (UNSBV) e, atualmente (fevereiro de 20I7), fornecem apoio logístico para mais de 37 missões de manutenção da paz.
} 
Segundo Coleman (20I4), o planejamento de desdobramento logístico da ONU parte de uma premissa que os Estados possuem a capacidade de providenciar seus próprios equipamentos para as fases iniciais da missão. Os atrasos de implantação nas missões são oriundos de dois fatores: I) a falta de capacidade dos países em prover os equipamentos e 2) a incapacidade de realizar a auto sustentação das tropas como prometido nos acordos iniciais com a Nações Unidas. Isso ocorre porque a maioria das forças de paz é proveniente de países em desenvolvimento, alguns dos quais não possuem toda a capacidade exigida pela ONU. Esses países relutam em investir e adquirir recursos até que se confirme pelas Nações Unidas a autorização para a missão, o que acarreta em grandes atrasos na implantação e no desdobramento de todos os meios logísticos na área de operação.

Com a finalidade de aumentar a prontidão das unidades logísticas, fornecendo incentivos para os Estados, a ONU busca reembolsar os países que contribuem com capacidades específicas que possam refletir diretamente na rapidez de desdobramento logístico na área da missão (United Nations 20I4C). Isto proporciona incentivos mais direcionados que não só facilitam um rápido "start-up" da missão, como também promovem uma contínua prontidão operacional por parte dos países contribuintes.

Coleman (20I4) compara as ações da ONU com a capacidade da OTAN de pressionar os Estados-Membros para cumprirem os compromissos firmados e se engajarem em ciclos de planejamentos logísticos de longo prazo para identificar as lacunas existentes que favoreçam, dentro de uma cooperação multinacional, as melhores condições logísticas de desdobramento. Nesta comparação, a ONU não possui condições de pressionar os Estados para que desenvolvam suas capacidades logísticas dentro do contexto atual da Organização.

\section{Apoio Logístico, Procurement (Aquisição) e Impactos para o país hospedeiro}

As organizações internacionais são conscientes de que o suporte logístico não apoia somente o pessoal de Operação de Paz no cumprimento de seu mandato, mas pode impactar diretamente os objetivos da missão como a estabilização e a reconstrução econômica do país anfitrião. Segundo Carnaham (2006), a decisão de "onde", "se" e "como" construir estradas, aeródromos, poços, como gerar eletricidade e como adquirir suprimentos pode ter efeitos profundos em uma área de conflito. Um relatório de 2010 da ONU (United Nations 20ıob) observou que os gastos com Operações de Paz têm o poten- 
cial para alavancar a economia local e sugeriu o aumento de aquisições locais como a melhor maneira de impactar positivamente a área de interesse.

O UN's Global Field Support Strategy (Estratégia de Apoio Global da ONU) define a plena utilização de "investimento nas capacidades locais e regionais" como um objetivo da missão (United Nations 20Iob). Um exemplo é o Regional Service Centre (Centro Regional de Serviços) em Uganda que facilita a contratação de empresas locais e regionais, facilitando e interligando a economia local com os serviços de aquisição da ONU.

O sistema de aquisições da ONU também reconhece que existem certos bens essenciais e de serviços que não estão disponíveis a partir da sede da ONU e por isso se prestam à aquisição local ou regional (United Nations 20I3a). Coleman (20I4) novamente coloca a OTAN como exemplo, citando o aumento de serviços e aquisições locais no Afeganistão.

No entanto, existem dois desafios para a utilização de contratos e aquisições locais. Um deles é que os Estados membros têm um grande interesse político e econômico em garantir contratos para suas empresas nacionais. Isso levou o sistema ONU a focar em contratos e aquisições de fornecedores em países em desenvolvimento ou em transição ${ }^{15}$ e não somente no país anfitrião.

A UN Procurement Division (Divisão de Aquisição da ONU) acompanhou o percentual de contratos em países em desenvolvimento ou em transição. No entanto, a conceituação desses países é muito ampla e dificulta o controle e a sistematização. Em 20I3, os contratos nesta categoria totalizaram US \$ I, 67 bilhões (representando 69\% dos contratos de manutenção de paz), incluindo US\$ 276 milhões em contratos com empresas russas, US\$ 313 milhões com fornecedores nos Emirados Árabes Unidos e US\$ 72 milhões com companhias kuaitianas (United Nations 2013b). A Divisão de Aquisição da ONU está buscando controlar separadamente os contratos levando em consideração a capacidade de contribuição financeira dos países (Coleman 20I4).

O segundo desafio é que, nem sempre, a contratação de fornecedores locais é de interesse da nação anfitriã. Em regiões nas quais os recursos locais (como alimentos e materiais de construção) são escassos, contratos celebrados podem privar as populações locais do acesso à essas necessidades básicas. Mesmo uma simples perfuração de um poço artesiano pode ser problemática se ela interferir nos sistemas de irrigação, como ocorreu com a OTAN no Afeganistão (Williams 2009) ou como aconteceu no Norte do Mali, ao obstruir

I5 O termo, geralmente, inclui os países da Europa Central e Oriental e da antiga União Soviética que estão emergindo de uma economia de tipo socialista para uma economia baseada no mercado. 
uma fonte de água fossilizada ${ }^{16}$.

Além disso, os contratantes locais podem se envolver em práticas que minam os objetivos de uma operação de paz. Clemente (2009) aponta, por exemplo, que forças do Talibã se beneficiaram de contratos locais estabelecidos pela OTAN no Afeganistão.

Conforme Coleman (20I4) para enfrentar esse desafio, a ONU tem o benefício de um sistema centralizado de aquisições. No entanto, o "UN Procurement Manual" (Manual de Aquisições da ONU) não lista explicitamente o impacto ao país anfitrião como um dos seus princípios orientadores; em vez disso, foca em temas como "melhor valor para o dinheiro", "justiça, integridade e transparência", "Concorrência internacional eficaz" e "o interesse da ONU” (United Nations 2013a, 『I.3.c).

Ainda de acordo com Coleman (20I4), a flexibilidade - e o grande desafio deste sistema - consiste em determinar o que realmente é o "melhor valor para o dinheiro". O manual supracitado identifica "fatores sem custos" que incluem a competência do fornecedor, o ambiente de mercado, os fatores de risco e a busca por um fornecedor "ético, justo e transparente"; o que abre espaço para subjetividades e juízos de valores. Além disso, quando a aquisição toma a forma de licitação com a solicitação de propostas onde são convidados fornecedores, essas são avaliadas de forma altamente técnica, levando em consideração a parte financeira e o atendimento das necessidades do produto ou serviço contratado. Os Estados-Membros têm questionado a ONU com o intuito de buscar uma melhor definição para o principio de "melhor valor para o dinheiro" (United Nations 20I3c). Os questionamentos incluem como esse princípio pode afetar fornecedores em países em desenvolvimento e em transição, e se os contratos mais sustentáveis deveriam ser encorajados (United Nations 20I4d).

\section{0 uso de tecnologias para reduzir os desafios logísticos}

A tecnologia pode ser usada para reduzir desafios no apoio logístico. Por exemplo, ela pode facilitar o supply chain management melhorando a informação sobre a circulação de pessoas, bens e serviços no país anfitrião. No âmbito da ONU, sistemas eletrônicos de gestão de combustível e inventário estão em fase de desenvolvimento e implantação (United Nations 20I4c.). De acordo com a publicação Center News (20I4), a ONU também tem desenvolvido a utilização de um Sistema de Informação Geográfica, para encontrar novas fontes de água para suas missões e para a exploração da geração de

I6 Em geologia chama-se agua fóssil ou paleoágua a água subterrânea de um aquífero. 
energia solar.

No entanto, outras tecnologias que poderiam diminuir os desafios de suporte de logística permanecem pouco exploradas. Por exemplo, o monitoramento com equipamentos, como câmeras fixas, câmeras em plataformas aéreas (incluindo veículos aéreos não tripulados) e radares de vigilância podem complementar os esforços do monitoramento humano (Dorn 20II). Seu uso permitiria uma maior concentração de pessoal internamente em bases a partir das quais poderiam ser realizadas patrulhas, reduzindo a demanda logística.

A ONU começou a usar algumas dessas tecnologias (incluindo veículos aéreos não tripulados) e poderia estender e padronizar seu uso. Ele é confiável e facilita o contato com fornecedores locais de suprimento e serviços (United Nations 20I3a). Para abastecimento local, as missões exigem informações sobre a capacidade dos fornecedores e estes precisam de informação sobre os requisitos da missão. Na África Oriental, os serviços que fornecem informações de mercado através de mensagens de texto foram desenvolvidos e são utilizados pelos agricultores para obter informações sobre os preços dos produtos. Ao mesmo tempo, os telefones celulares começaram a ser usados para receber e fazer pagamentos. A tecnologia pode acelerar o pagamento e ajudar a proteger fornecedores vulneráveis (mulheres, por exemplo) contra roubo e corrupção (Twonbei 2013).

A longo prazo, “a impressão 3-D” irá revolucionar alguns aspectos chaves do apoio logístico. A tecnologia existente já permite a impressão de objetos em metal e em plástico, abrindo a possibilidade do pessoal destacado em áreas remotas de imprimir uma grande variedade de itens que vão desde peças de reposição a dispositivos médicos personalizados ${ }^{17}$.

Para operações de paz, a impressão 3-D pode oferecer uma ótima solução para a variedade e diversificação de equipamentos dos diferentes países que integram uma missão, simplesmente alterando o projeto da impressão. É pouco provável que essa tecnologia possa substituir as cadeias de suprimento convencionais em um futuro próximo, mas pode diminuir drasticamente a necessidade de um extenso estoque de material. A impressão 3-D potencialmente pode fornecer uma solução provisória, gerando uma capacidade local. Criar-se-ia, dessa forma, uma flexibilidade e uma capacidade até que o supply chain pudesse suprir a demanda (Sherman 20I2).

A ONU convocou um Painel de Peritos em Tecnologia e Inovação em Missões de Manutenção da Paz sob sua responsabilidade. As deliberações do

I7 Drushal (20I0) analisa o impacto da tecnologia sobre a logística das Forças Armadas dos EUA, especialmente na Marinha. 
painel incluem considerações sobre as tecnologias que facilitam o apoio logístico. No longo prazo, no entanto, um corpo mais permanente deve ser criado no âmbito do Secretariado da ONU para monitorar e avaliar tecnologias que podem beneficiar as operações de paz dentro do campo logístico (United Nations 20I4b).

\section{Considerações Finais}

O apoio logístico eficiente é crucial para permitir que agentes civis, militares e policiais desdobrados em operações de paz possam cumprir seus mandatos. A forma como esse apoio é realizado causa impactos nos países anfitrião e contribuinte.

Em operações de paz, o apoio logístico emana de uma variedade de fontes, incluindo as capacidades de autossuficiência de contingentes desdobrados, capacidade logística dos Estados contribuintes, as organizações internacionais que participam da coordenação e a nação anfitriã, empresas comerciais e doadores.

O apoio logístico busca aperfeiçoar seus procedimentos podendo dar sustentação para uma rápida implementação de uma missão, otimizando o impacto da prestação ao país anfitrião, e incorporando novas tecnologias para que as operações de paz não sofram uma solução de continuidade e tenham seus mandados cumpridos.

\section{REFERÊNCIAS}

Aguilar, Sergio Luiz Cruz. 2015. “A Participação do Brasil nas Operações de Paz: passado, presente e futuro”. Brasiliana - Journal for Brazilian Studies 3 (2): II3-I4I.

Baig, Kamran. 20I0. Logistical Support to United Nations Peacekeeping Operations: An introduction. Williamsburg: Peace Operations Training Institute.

Balcik, Barcu, Benita Beamon, Caroline Krejci, Kyle Muramatsu, and Magaly Ramirez. 2010. "Coordination in humanitarian relief chains: Practices, challenges and opportunities". International Journal of Production Economics I26: 22-34.

Banomyong, Ruth, and Apichat Sodapang. 20I2. "Relief Supply Chain Planning: Insights from Thailand". In Relief Supply Chain Management for Disasters: Humanitarian Aid and Emergency Logistics. Hershey: 
Business Science Reference.

Barber, Elizabeth. 2012. "Military Involvement in Humanitarian Supply Chain". In Relief Supply Chain Management for Disasters: Humanitarian Aid and Emergency Logistics. Hershey: Business Science Reference.

Beresford, Anthony, and Stephen Pettit. 2012. "Humanitarian Aid Logistics: The Wenchuan and Haiti Earthquakes Compared". In: Relief Supply Chain Management for Disasters: Humanitarian Aid and Emergency Logistics. Hershey: Business Science Reference.

Boutellis, Arthur E Adam C. Smith. 20I4. Engineering Peace: The Critical Role of Engineers in UN Peacekeeping. New York: International Peace Institute.

Boutros-Ghali, Boutros. 1992. An Agenda for Peace: Preventive Diplomacy, Peacemaking and Peace-keeping. United Nations official document A/47/277 - S/24IIII, I7 June I992. New York: Department of Public Information.

. I996. ONU: Uma Agenda para o Desenvolvimento. Palestra proferida em fevereiro de i996. São Paulo: IEA-USP. http://www.iea.usp.br/ iea/artigos/boutros-ghalionu.pdf.

Brooks, Doug, and Fiona Mangan. 20II. "Modern Use of Contractors in Peace and Stability Operations". Brown Journal of World Affairs XVIII (I): I63-I76.

Carnahan, Michael, William Durch, and Scott Gilmore. 2006. Economic Impact of Peacekeeping. New York: Peace Dividend Trust for the Peacekeeping Best Practices Section, UN Department of Peacekeeping Operations.

Clemente, Dave, and Ryan Evans. 2014. "Wartime Logistics in Afghanistan and Beyond". Chatham House Report. January. https://www.chathamhouse.org/sites/files/chathamhouse/home/chatham/public_html/ sites/default/files/afghanistan_clemente.pdf.

Coleman, Katharina. 20I4. Political Economy of UN Peacekeeping. New York: International Peace Institute.

. 20I4. "Overcoming Logistics Dificulties in Complex Peace Operations in Remote Areas”. Challenges Forum. October I4-I6, Beijing, China.

Dorn, Walter. 20II. Keeping Watch: Monitoring Technology and Innovation in UN Peace Operations. Tokyo: United Nations University Press.

Drushal, Jon, and Michael Llenza. 2012. "3-D Printing revolution in Military Logistics". Atlantic Council. November 20. http://www.atlanticcouncil. org/blogs/new-atlanticist/3d-printing-revolution-in-military-logistics. 
Heaslip, Graham, and Elizabeth Barber. 20I4. "Using the military in disaster relief: systemising challenges and opportunities". Journal of Humanitarian Logistics and Supply Chain Management 4 (I): 6o-8I.

Kress, Moshe. 2002. Operational Logistics: The Art and Science of Sustaining Military Operations. New York: Springer Science; Business Media New York.

Leslie, Don. 20I2. Operational logistical support of UN peacekeeping missions. UN: Peace Operations Training Institute.

Marginean, Valentin. 20I4. Host Nation Support during operations and exercises. NATO Logistic Branch, SHAPE.

Martins Filho, Elias Rodrigues e Eduardo Uziel. 20I5. "As operações de manutenção da paz e o Secretariado das Nações Unidas". Política Externa 24 (I).

Neves, Gilda. 2009. Comissão das Nações Unidas para Consolidação da Paz: perspectiva brasileira. Brasília: FUNAG.

OTAN. 20I0. "Afghan First Policy". NATO. April 23. http://www.nato.int/cps/ en/natolive/official_texts_62851.htm.

Patriota, Antonio de Aguiar. 1998. O Conselho de Segurança após a Guerra do Golfo: a Articulação de um Novo Paradigma de Segurança Coletiva. Brasília: FUNAG.

Sebbah, Samir, Abdeslem Boukhtouta, Jean Berger, and Ahmed Ghanmi. 2013. "Military Logistics Planning in Humanitarian Relief Operations". In Humanitarian and Relief Logistics: Research Issues, Case Studies and Future Trends. New York: Springer.

Sherman, Jake, Alischa Kugel, and Andrew Sinclair. 2012. "Overcoming Helicopter Force Generation Challenges for UN Peacekeeping Operations". International Peacekeeping I9 (I): 77-92.

Twombey, Matt. 20I3. “Cashless Africa: Kenya's smash success with mobile money”. CNBC. November II. http://www.cnbc.com/20I3/II/II/cashless-africa-kenyas-smash-success-with-mobile-money.html.

United Nations. 1994. Resolutions and Decisions adopted by the General Assembly during its 49th session: GAOR, 49th Session, Supplement No. 49. http://research.un.org/en/docs/ga/quick/regular/49. . 2003. Handbook on United Nations Multidimensional Peacekeeping Operations (PKO). New York: Department of Peacekeeping Operations. 2010a. United Nations Peacekeeping Operations: Principles and Guidelines. New York: Department of Peacekeeping Operations. 2oIob. Global Field Support Strategy. A/64/633. January 26. 
20I3a. United Nations Procurement Manual. July I.

. 2013b. United Nations Procurement Division statistics. http://www.un.org/Depts/ptd/procurement-bycountry-table-detail/2013.

. 2013c. Advisory Committee on Administrative and Budgetary Questions. Comprehensive Report on United Nations Procurement Activities. A/67/80I. March I8.

. 2014a. Overview of the Financing of the United Nations Peacekeeping Operations. A/68/73I. January 3I.

. 20I4b. USGs Announce Expert Panel on Technology and Innovation in UN Peace- keeping. Press release. June 4.

20I4c. United Nations Secretary-General, Results of the revised survey to establish the standard rate of reimbursement for troop-contributing countries. A/68/8I3, 『66. March 26.

. 20I4d. General Assembly. Resolution 68/263. April 28.

. 20I4e. United Nations ACABQ. Observations and recommendations on cross-cutting issues related to peacekeeping operations. A/68/782, 『7I. May 5 .

Williams, David B. 2009. "Finding water in the heart of darkness: Afghanistan's ongoing water challenges". EARTH Magazine. July. https://www.earthmagazine.org/article/finding-water-heart-darkness-afghanistans-ongoing-water-challenges.

Zeimpekins, Vasileios, Soumia Ichoua, and Ioannis Minis. 20I3. "Humanitarian Logistics: An Opportunity for Research in Operations to Save Lives and Limit the Effects of Devastation". In Humanitarian and Relief Logistics: Research Issues, Case Studies and Future Trends. New York: Springer.

\section{RESUMO}

O aumento do número e da complexidade das missões de operações de paz sob a égide da ONU acarretou desafios de implementação e operacionalização logísticos. Objetiva-se entender e investigar a complexidade do apoio logístico nas missões de 
operações de paz, suas implicações e reflexos.

\section{PALAVRAS-CHAVE}

Logística; Supply chain; Complexidade; Missão de Paz das Nações Unidas.

Recebido em 29 de março de 2017. Aprovado em 25 de julho de 2017. 